\title{
Relationships among satisfaction, treatment motivation, and expectations in orthodontic patients: a prospective cohort study
}

\section{Weihong $\mathrm{Li}$ \\ Shimei Wang \\ Yanzhen Zhang}

The Second Affiliated Hospital, Zhejiang University School of Medicine, Hangzhou, Zhejiang, People's Republic of China
Correspondence: Yanzhen Zhang The Second Affiliated Hospital, Zhejiang University School of Medicine, 88 Jiefang

Road, Hangzhou, Zhejiang 310009 ,

People's Republic of China

Tel +8657l 87783608

Email zhangyanzhenI@I26.com
This article was published in the following Dove Press journal:

Patient Preference and Adherence

4 April 2016

Number of times this article has been viewed

Background: Few research projects have looked at patient satisfaction with treatment outcome and factors contributing to satisfaction. The aim of this study was to examine treatment motivation and expectation associated with treatment-outcome satisfaction in a group of adolescent nonextraction orthodontic patients. We hypothesized that there would be significant correlations among treatment-outcome satisfaction, motivation, and expectations.

Subjects and methods: A sample of 120 patients who received orthodontic treatment at the Second Affiliated Hospital of Zhejiang University School of Medicine completed two questionnaires. Before treatment, questionnaire 1 was given to patients to assess treatment motivation and expectations. When treatment had been completed, questionnaire 2, concerning treatment satisfaction, was assessed. Spearman's rank correlation and regression analyses were used to assess the relationships among treatment satisfaction, expectations, and motivation.

Results: A total of 110 patients completed the two questionnaires. There was a tendency toward significant correlations between treatment motivation and overall satisfaction with treatment ( $\beta$-coefficient $-0.264,95 \%$ confidence interval -0.456 to $2.314 ; P<0.001$ ). However, correlations among treatment motivation and satisfaction with changes made and satisfaction with one's appearance posttreatment were more fragmented. No relationship between treatment expectation and satisfaction was found ( $\beta$-coefficient -0.126 ; $95 \%$ confidence interval -0.024 to $0.524 ; P>0.05$ ).

Conclusion: Motivation was correlated with satisfaction with treatment outcome. Patients' expectations had no correlation with treatment satisfaction.

Keywords: motivation, orthodontic treatment, expectation, treatment-outcome satisfaction

\section{Background}

Based on orthodontic treatment indices, approximately $30 \%$ of patients have malocclusions that are considered in great need of orthodontic treatment, and the number of adolescents receiving orthodontic treatment worldwide has increased considerably. ${ }^{1-4}$ Nonetheless, exceptionally few research projects have looked at patient satisfaction with treatment outcome and the factors contributing to satisfaction. ${ }^{5}$ Research has shown that only $34 \%$ of orthodontic patients were totally satisfied, $62 \%$ were relatively satisfied, and $4 \%$ were actually dissatisfied. ${ }^{6}$ This finding raises the question whether there is a way that orthodontists could identify - prior to orthodontic treatment - which patients might be less satisfied with treatment outcome.

We know that patient satisfaction after orthodontic treatment is influenced by a number of factors, such as sex, age, duration of treatment, compliance, and dentofacial improvement, ${ }^{7-9}$ but so far no correlations have been found among treatment expectation, motivation, and satisfaction with treatment outcome. 
In previous research, the relationship between adolescent patients' motivation for orthognathic surgery based on their "possible selves" and their satisfaction with the surgery outcomes was analyzed. ${ }^{10}$ It was found that the more energized the patients had been before the surgery, the more satisfied they were with the outcomes, and the more they had focused on esthetic changes and on improved functioning, the more satisfied they were with the treatment outcomes. Bos et $\mathrm{al}^{11}$ concluded that patients who are satisfied with the appearance of their teeth have different expectations of orthodontic treatment than those who are dissatisfied.

Earlier studies also showed that male patients have different expectations of orthodontic treatment than female patients. Although female patients seek treatment to improve their appearance and self-confidence, male patients want treatment to improve their social well-being. ${ }^{12-16}$ Therefore, to be able to better explain and predict patient satisfaction after orthodontic treatment, it is important to get a clear understanding of the motivations and expectations of patients before initiating any treatment.

The aim of the present study was to identify patient and treatment factors associated with patient satisfaction in a group of adolescent patients. It was hypothesized that there would be significant correlations among treatment-outcome satisfaction, motivation, and expectations.

\section{Subjects and methods Subjects}

The design of this study was a prospective cohort study. A total of 120 (60 girls and 60 boys, mean age 13.3 years, standard deviation [SD] 1.73 years) patients were consecutively recruited from the Second Affiliated Hospital of Zhejiang University School of Medicine. Patients needed to have met the following criteria: 1) adolescence, 2) no history of orthodontic treatment, (3) no previous orthognathic surgery, (4) class I molar relationship - no bone problem, (5) nonextraction treatment, and (6) no severe dentofacial anomalies or system diseases, such as a cleft lip or palate. Patients who did not meet the criteria were excluded. All patients were treated using a standard straight-wire technique with a 0.022-inch slot size designed for continuous light forces (Victory series; 3M Unitek, Monrovia, CA, USA). The patients were nonextraction treated, beginning with the same sequence of 0.012-, 0.014-, 0.016-, and 0.018-inch SS arch wires. Treatment duration was $10.3 \pm 3.6$ months. After treatment, all patients wore Hawley retainers.

\section{Approval and consent}

The ethics committee of the Second Affiliated Hospital, Zhejiang University School of Medicine approved the protocol (2013-012). Each individual asked to participate was informed about the study according to the guidelines of the Declaration of Helsinki, and informed consent from the patients guardians was achieved by means of written approval to participate.

\section{Questionnaires}

Self-report items from questionnaires previously found to be reliable and valid were used. ${ }^{17,18}$ Questionnaire 1 contained seven items about treatment motivation and four about expectations. All questions were graded on a visual analog scale (VAS) with the end phrases "not at all" and "very much". The questions, including median values and interquartile ranges, are presented in Table 1.

Questionnaire 2 was administered after active treatment at the first rescheduled visit in the retention phase (after 3 months), and included three questions concerning satisfaction with treatment outcome graded on a VAS with the end phrases "not at all" and "very much". The questions,

Table I Questionnaire concerning treatment motivation and expectations assessed on a visual analog scale prior to treatment start

\begin{tabular}{|c|c|c|}
\hline Variables & Mean & $\begin{array}{l}\text { Standard } \\
\text { deviation }\end{array}$ \\
\hline \multicolumn{3}{|l|}{ Treatment motivation } \\
\hline I. Do your teeth bother you? & 35.6 & 15.2 \\
\hline 2. If it were possible, how much would you like to change the appearance of your teeth? & 82.5 & 8.9 \\
\hline 3. Do you think your teeth need straightening? & 80.1 & 7.9 \\
\hline 4. How motivated are you to have orthodontic treatment with braces? & 76.8 & 8.6 \\
\hline 5. Do you think orthodontic treatment will be good for your teeth? & 90.1 & 5.6 \\
\hline 6. Have you been properly informed about the orthodontic treatment? & 93.8 & 5.1 \\
\hline 7. Is it your own decision to undergo orthodontic treatment? & 84.5 & 6.7 \\
\hline \multicolumn{3}{|l|}{ Treatment expectations } \\
\hline 8. Do you think it is going to be difficult to wear braces? & 35.4 & 10.3 \\
\hline 9. Are you worried about having orthodontic treatment? & 20.3 & 15.5 \\
\hline 10. Are you worried about how you are going to look with braces on? & 25.6 & 16.2 \\
\hline II. Have you ever been teased about the appearance of your teeth? & 2.5 & 2.3 \\
\hline
\end{tabular}


Table 2Questionnaire concerning treatment-outcome satisfaction assessed on a visual analog scale at the retention phase

\begin{tabular}{lll}
\hline Variables & Mean & $\begin{array}{l}\text { Standard } \\
\text { deviation }\end{array}$ \\
\hline $\begin{array}{l}\text { Treatment-outcome satisfaction } \\
\begin{array}{l}\text { I. Considering everything, are you satisfied } \\
\text { with your orthodontic treatment? }\end{array}\end{array}$ & 91.6 & 7.5 \\
$\begin{array}{l}\text { 2. Are you satisfied with the changes made } \\
\text { during treatment? }\end{array}$ & 95.2 & 4.6 \\
$\begin{array}{l}\text { 3. Are you satisfied with the appearance } \\
\text { of your teeth after treatment? }\end{array}$ & 94.8 & 3.7 \\
\hline
\end{tabular}

including median values and interquartile ranges, are presented in Table 2.

\section{Statistical analysis}

Mean and SD were calculated for variables assessed on a VAS (ordinal data). For assessments of the correlation among patient satisfaction, treatment expectations, and motivation, the Spearman's rank correlation was utilized. Next, a multiple regression analysis was performed to estimate the effect of treatment expectations and motivation on satisfaction of orthodontic treatment. The level of statistical significance was set at $P<0.05$.

\section{Results}

Six patients dropped out of the trial, and four patients did not complete questionnaire 2 . A total of 110 patients completed the trial: 54 boys and 56 girls (mean age 16.9 years, SD
1.78 years). The response rate for each item varied between $90 \%$ and $100 \%$.

There was a significant correlation between treatment motivation and overall satisfaction with treatment (Table 3 ), although correlations between treatment motivation and satisfaction with changes made and satisfaction with one's appearance posttreatment were more fragmented. No correlation was found among the patient's own decision to start treatment, patients who thought their teeth bothered them, and satisfaction with treatment outcome. There was no significant correlation between treatment expectations and satisfaction (Table 3).

Following adjustment for confounding variables, higher impacts on treatment satisfaction were observed for patients who thought their teeth bothered them and wanting to change their dental appearance (Table 4). However, we found that treatment expectations were not significantly associated with satisfaction after treatment.

\section{Discussion}

Patient motivation and expectation related to patient satisfaction are controversial in the literature. A small number of studies have examined this issue. In the present study, we found that motivation was the factor correlated with treatmentoutcome satisfaction. However, no significant correlations were found between treatment-outcome satisfaction and expectations of orthodontic treatment.

Table 3 Correlations among treatment-outcome satisfaction, motivation, and expectations prior to treatment

\begin{tabular}{|c|c|c|c|c|c|c|}
\hline \multirow[t]{3}{*}{ Variables } & \multicolumn{6}{|c|}{ Treatment-outcome satisfaction } \\
\hline & \multicolumn{2}{|c|}{$\begin{array}{l}\text { Considering } \\
\text { everything, are } \\
\text { you satisfied with } \\
\text { your orthodontic } \\
\text { treatment? }\end{array}$} & \multicolumn{2}{|c|}{$\begin{array}{l}\text { Are you satisfied } \\
\text { with the changes } \\
\text { made during } \\
\text { treatment? }\end{array}$} & \multicolumn{2}{|c|}{$\begin{array}{l}\text { Are you satisfied } \\
\text { with the } \\
\text { appearance of } \\
\text { your teeth after } \\
\text { treatment? }\end{array}$} \\
\hline & $r$ & P-value & $r$ & $P$-value & $r$ & $P$-value \\
\hline \multicolumn{7}{|l|}{ Treatment motivation } \\
\hline I. Do your teeth bother you? & -0.128 & 0.534 & -0.128 & 0.548 & -0.121 & 0.459 \\
\hline $\begin{array}{l}\text { 2. If it were possible, how much would you like to change the } \\
\text { appearance of your teeth? }\end{array}$ & 0.4 & $0.001 * *$ & 0.348 & $0.001 * *$ & 0.234 & 0.354 \\
\hline 3. Do you think your teeth need straightening? & 0.312 & $0.00 I^{* *}$ & 0.234 & $0.014^{*}$ & 0.234 & 0.189 \\
\hline 4. How motivated are you to have orthodontic treatment with braces? & 0.33 & $0.035^{*}$ & 0.087 & 0.345 & 0.213 & $0.035^{*}$ \\
\hline 5. Do you think orthodontic treatment will be good for your teeth? & 0.152 & $0.001 * *$ & 0.324 & $0.024^{*}$ & 0.124 & $0.034 *$ \\
\hline 6. Have you been properly informed about the orthodontic treatment? & 0.104 & $0.016 *$ & 0.124 & $0.043^{*}$ & 0.245 & 0.075 \\
\hline 7. Is it your own decision to undergo orthodontic treatment? & 0.045 & 0.075 & 0.155 & 0.216 & -0.125 & 0.077 \\
\hline \multicolumn{7}{|l|}{ Treatment expectations } \\
\hline 8. Do you think it is going to be difficult to wear braces? & 0.148 & 0.426 & -0.157 & 0.46 & -0.124 & 0.357 \\
\hline 9. Are you worried about having orthodontic treatment? & 0.124 & 0.075 & -0.124 & 0.235 & -0.128 & 0.214 \\
\hline 10. Are you worried about how you are going to look with braces on? & 0.342 & 0.421 & -0.167 & 0.405 & -0.152 & 0.324 \\
\hline II. Have you ever been teased about the appearance of your teeth? & -0.124 & 0.325 & -0.126 & 0.254 & -0.125 & 0.124 \\
\hline
\end{tabular}

Notes: $* P<0.05 ; * * P<0.01$. 
Table 4 Results of multiple regression analysis for the treatment motivation and expectation of impacts (treatment satisfaction)

\begin{tabular}{|c|c|c|c|}
\hline \multirow[t]{2}{*}{ Independent variables } & \multicolumn{3}{|c|}{ Multivariate linear regression } \\
\hline & $\beta$-Coefficient & $95 \% \mathrm{Cl}$ & P-value \\
\hline \multicolumn{4}{|l|}{ Treatment motivation } \\
\hline I. Do your teeth bother you? & -0.264 & -0.456 to 2.314 & $0.001 * *$ \\
\hline 2. If it were possible, how much would you like to change the appearance of your teeth? & 0.364 & $0.021-0.652$ & $0.001 * *$ \\
\hline 3. Do you think your teeth need straightening? & 0.354 & $0.452-0.869$ & 0.232 \\
\hline 4. How motivated are you to have orthodontic treatment with braces? & 0.263 & $0.124-0.961$ & $0.026^{*}$ \\
\hline 5. Do you think orthodontic treatment will be good for your teeth? & 0.264 & $0.123-0.687$ & $0.001 * *$ \\
\hline 6. Have you been properly informed about the orthodontic treatment? & 0.125 & $0.120-0.872$ & $0.012^{*}$ \\
\hline 7. Is it your own decision to undergo orthodontic treatment? & 0.102 & $0.234-0.854$ & 0.354 \\
\hline \multicolumn{4}{|l|}{ Treatment expectations } \\
\hline 8. Do you think it is going to be difficult to wear braces? & 0.263 & $0.287-1.002$ & 0.652 \\
\hline 9. Are you worried about having orthodontic treatment? & 0.314 & $0.412-1.213$ & 0.254 \\
\hline 10. Are you worried about how you are going to look with braces on? & 0.231 & $0.425-1.254$ & 0.326 \\
\hline II. Have you ever been teased about the appearance of your teeth? & -0.126 & -0.024 to 0.524 & 0.124 \\
\hline
\end{tabular}

Notes: $* P<0.05 ; * * P<0.01$

Abbreviation: $\mathrm{Cl}$, confidence interval.

Patient satisfaction with orthodontic treatment has had no definitive outcome in the literature. ${ }^{19}$ This can be explained by the different motivations and expectations of patients receiving orthodontic treatment. Most studies report functional, esthetic, and social reasons as the main motivations to seek orthodontic treatment. ${ }^{5,12-16}$

In the present study, motivation to undergo treatment showed correlations with treatment satisfaction, which is also in agreement with the findings of Bos et al, who concluded that the more focused the patient was prior to treatment, the more satisfied he/she was with the outcome. ${ }^{11}$ However, it is interesting that the patients reported higher correlations with esthetic aspects of their treatment outcomes compared with functional aspects. This finding is consistent with the results of other studies that showed that esthetic considerations were the primary reason for orthodontic treatment. ${ }^{20,21}$ These findings are not surprising, given that research showed that the face is a crucial characteristic in the development of a person's self-esteem and self-image. ${ }^{22,23}$ It seems understandable, therefore, that the patients were on average more energized by and focused on esthetics than functioning.

These findings offer a potential strategy to improve patients' orthodontic treatment satisfaction. Given that possible pretreatment self-considerations correlate with posttreatment satisfaction, a first step would be to assess patients' possible selves during the screening appointment. Assessing these possible selves can be achieved by communicating with the patient and his/her parents about these considerations. Parents are clearly aware of their child's possible self-considerations and could thus be a valuable source of information. The second step would be to shape the patients' possible selves in a way that the patients become more excited about how they will look after the braces and how they will be able to function. Focusing patients on how they will look and making them excited about the ultimate treatment outcome should result in increased treatment satisfaction.

In addition to exploring these issues prior to treatment, it might also be worthwhile to keep these issues in mind when communicating with a patient during treatment. Patients' motivation is dynamic, and can be affected throughout the course of the treatment. Even if patients had not been energized and focused prior to their treatment, orthodontists and their staff could encourage their patients to engage in possible self-related reflections during the treatment. As a result, patients who might have been at risk of being dissatisfied with their treatment outcome might become increasingly more motivated by thinking about the future.

It is interesting to find that neither expectations nor worries about future treatment correlated with treatment satisfaction. One possible explanation could be that orthodontic treatment can affect dental performance positively, which can lead to higher levels of satisfaction. Another reason may be that this study only included adolescent subjects. As we all know, treatment concern was different in adolescents and adults. This indication of a correlation between expectations and satisfaction with treatment is interesting to consider for future research in both adolescents and adults.

\section{Limitations}

Some limitations of the results must be noted. First, the findings reflect only the satisfaction of patients treated at the Second Affiliated Hospital of Zhejiang University School of Medicine. Therefore, the results cannot be generalized to orthodontic patients in general. We will include more people 
from different socioeconomic backgrounds, cultures, and ethnicity in further research. Second, the questionnaires had only a few questions targeting two domains, which means that some interesting issues were dealt with only superficially. Therefore, orthodontists should try to gain as complete an understanding as possible of patient motivations and expectations before treatment. Finally, the highest correlation coefficient found was 0.4 ; this is statistically significant, but may not be the major determinant of the treatment outcome. Clinically relevant $r$-values should be 0.5 or $0.6 .^{24}$

\section{Conclusion}

Motivation was the factor correlated with treatment-outcome satisfaction. However, no significant correlations were found between treatment-outcome satisfaction and expectations of orthodontic treatment. The results of this study suggest that communicating with patients about their expectations and motivations might ultimately lead to higher satisfaction with their treatment. A relationship between treatment satisfaction and motivation for orthodontic treatment was found. In the future, this study can be applied to improve treatment satisfaction. Therefore, we advise that orthodontists know their patients' motivation for orthodontic treatment before treatment.

\section{Acknowledgment}

This research was partially supported by the Zhejiang Provincial Natural Science Foundation of China (Y2110400).

\section{Disclosure}

The authors report no conflicts of interest in this work.

\section{References}

1. Borzabadi-Farahani A. An insight into four orthodontic treatment need indices. Prog Orthod. 2011;12:132-142.

2. Borzabadi-Farahani A, Borzabadi-Farahani A, Eslamipour F. Orthodontic treatment needs in an urban Iranian population, an epidemiological study of 11-14 year old children. Eur J Paediatr Dent. 2009;10:69-74.

3. Borzabadi-Farahani A. Agreement between the index of complexity, outcome, and need and the dental and aesthetic components of the index of orthodontic treatment need. Am J Orthod Dentofacial Orthop. 2011; 140:233-238.

4. Dimberg L, Lennartsson B, Arnrup K, Bondemark L. Prevalence and change of malocclusions from primary to early permanent dentition: a longitudinal study. Angle Orthod. 2015;85:728-734.

Patient Preference and Adherence

\section{Publish your work in this journal}

Patient Preference and Adherence is an international, peer-reviewed, open access journal that focuses on the growing importance of patient preference and adherence throughout the therapeutic continuum. Patient satisfaction, acceptability, quality of life, compliance, persistence and their role in developing new therapeutic modalities and compounds to optimize
5. Perillo L, Esposito M, Caprioglio A, Attanasio S, Santini AC, Carotenuto M. Orthodontic treatment need for adolescents in the Campania region: the malocclusion impact on self-concept. Patient Prefer Adherence. 2014;8:353-359.

6. Al-Omiri M, Alhaija E. Factors affecting patient satisfaction after orthodontic treatment. Angle Orthod. 2006;76:422-431.

7. Bos A, Vosselman N, Hoogstraten J, Prahl-Andersen B. Patient compliance: a determinant of patient satisfaction? Angle Orthod. 2005;75: $526-531$.

8. Wheeler TT, McGorray SP, Yurkiewicz L, Keeling SD, King GJ. Orthodontic treatment demand and need in third and fourth grade school children. Am J Orthod Dentofacial Orthop. 1994;106:22-23.

9. Shaw WC. Factors influencing the desire for orthodontic treatment. Eur J Orthod. 1981;3:151-162.

10. Meade EA, Inglehart MR. Young patients' treatment motivation and satisfaction with orthognathic surgery outcomes: the role of "possible selves". Am J Orthod Dentofacial Orthop. 2010;137:26-34.

11. Bos A, Hoogstraten J, Prahl-Andersen B. Expectations of treatment and satisfaction with dentofacial appearance in orthodontic patients. Am J Orthod Dentofacial Orthop. 2003;123:127-132.

12. Williams AC, Shah H, Sandy JR, Traves HC. Patients' motivations for treatment and their experiences of orthodontic preparation for orthognathic surgery. J Orthod. 2005;32:191-202.

13. Kiyak HA, Hohl T, Sherrick P, West RA, McNeil RW, Bucher F. Sex differences in motives for and outcomes of orthognathic surgery. J Oral Surg. 1981;29:757-768.

14. Nurminen L, Pieliä T, Vinkka-Puhakka H. Motivations for and satisfaction with orthodontic surgical treatment: a retrospective study of 28 patients. Eur J Orthod. 1999;21:79-87.

15. Phillips C, Broder HL, Bennet ME. Dentofacial disharmony: motivations for seeking treatment. Int J Adult Orthodon Orthognath Surg. 1997;12: $7-15$.

16. Hiemstra R, Bos A, Hoogstraten J. Patients' and parents' expectations of orthodontic treatment. J Orthod. 2009;36:219-228.

17. Feldmann I, List T, John M, Bondemark L. Reliability of a questionnaire assessing experiences of orthodontic treatment in adolescents. Angle Orthod. 2007;77:311-317.

18. Xue D, Gong Z, Zhu J. Investigate and analysis of satisfaction to orthodontic treatment in adolescent patients. Mod Med. 2014; $12: 231-221$

19. Birkeland K, Boe OE, Wisth PJ. Relationship between occlusion and satisfaction with dental appearance in orthodontically treated and untreated groups: a longitudinal study. Eur J Orthod. 2000;22:509-518.

20. Williams AC, Shah H, Sandy JR, Travess HC. Patients' motivations for treatment and their experiences of orthodontic preparation for orthognathic surgery. J Orthod. 2005;32:191-202.

21. De Oliveira CM, Sheiham A. The relationship between normative orthodontic treatment need and oral health-related quality of life. Community Dent Oral Epidemiol. 2003;31:426-436.

22. Hershon LE, Giddon DB. Determinants of facial profile self-perception. Am J Orthod. 1980;78:279-295.

23. Berscheid E, Walster E, Bohrnstedt G. Body image. Psychol Today. 1973;7:119-131.

24. Borzabadi-Farahani A, Borzabadi-Farahani A, Eslamipour F. The relationship between the ICON index the dental and aesthetic components of the IOTN index. World J Orthod. 2010;11:43-48.

\section{Dovepress}

clinical outcomes for existing disease states are major areas of interest for the journal. This journal has been accepted for indexing on PubMed Central. The manuscript management system is completely online and includes a very quick and fair peer-review system, which is all easy to use. Visit http://www. dovepress.com/testimonials.php to read real quotes from published authors. 